\section{The Geriatric Depression Scale: feasibility of cardbased-administration}

Editor - Depression is common in the elderly, and is an important cause of morbidity. Routine screening in healthcare settings may aid in detection.' It can affect cognitive status, well being, recovery from illness and compliance with medications.

The Geriatric Depression Scale (GDS) is an effective questionnaire, which was originally designed to be selfadministered. ${ }^{23}$

This, however, can be difficult in the elderly. ${ }^{4}$ Previously the use of laminated cards to administer another depression scale, the BASDEC, was shown to be reliable. ${ }^{5}$ The aim of our study was to determine if card-based administration of this scale correlated with verbal administration.

We asked 42 patients attending the Age Related Healthcare Day Hospital to take part in our study. The inclusion criteria were aged over 65 years, MMSE of $16 / 30$ or more, and English speaking. We excluded those who had dysphasia, dyslexia, illiteracy or visual impairment such that they could not read large print. A history of depression did not affect selection.

The patients were randomised, using a standard random sequence, as to whether they underwent verbal or cardbased administration of the GDS first. An MMSE was performed. The GDS was then administered to each patient, by two interviewers in succession, both verbally and using cards. All those with a score of $>11$ were followed up in relation to treatment of depression.

Three people were excluded from the study. Two could not read the large print and one patient could not complete the interview due to fatigue. Using a paired t test $(p=0.13)$, there was no significant difference between card-based and verbal administration of the GDS. Both methods of administration correlated well $(r=0.84)$.
We found that a card-based GDS correlates well with a verbally administered GDS, and could be used in a similar manner to the BASDEC scale.

The use of a card based depression scale allows for administration in a general hospital ward without the questions and answers being overheard. It may allow for a degree of standardisation and can also be conveniently carried in a white coat pocket. However, the assessors in this study all reported feeling constrained by use of the card based technique. It was felt that older people were unable to express their exact feelings about each of the questions, leading to frustration on their part.

Perhaps rather than muting the questions, we should more seriously consider that when sensitive questions are being asked, both cognitive and affective, an interview should not take place at the bedside, but rather in a separate interview room. Future studies might explore older peoples' preference for the mode of administration of screening questionnaires.

Linda Brewer, MB,

Roisin Connolly, MB,

Danny Smith, MB, interns,

Desmond O'Neill, MD Associate Professor,

Department of Gerontology,

Trinity College Dublin,

Dublin 2,

Ireland.

This letter was published in the September issue without the full list of authors included.

References

1. Burns A, Lawlor B, Craig S: Rating scales in old age psychiatry. BJ Psych 2002; 180: $161-167$

2. Koenig GH, Meador KG, Cohen HJ, Blazer DG: Self-rated depression

scales and screening for major depression in the older hospitalised patient with medical illness. JAGS 1998; 36: 699-706

3. O'Riordan T, Hayes J, O'Neill D, Walsh JB, Coakley D. The effect of mild to moderate dementia on the Geriatric Depression Scale and on the General Health Questionnaire in the hospitalised elderly. Mt J Geriatr Psychiatr 1990; 4: 17-21

4. O'Neill D, Rice I, Blake P, Walsh JB, Coakley D. The Geriatric Depression Scale: rater 4. O'Neill D, Rice I, Blake P, Walsh JB, Coakley D. The Geriatric Depression Scal
administered or self administered? Int J Geriatr Psychiatr 1992; 7:511-515

5. Adshead F, Cody DD, Pitt B. BASDEC: a novel screening instrument for depression in elderly medical inpatients. BMJ 1992; 305: 397.

appears unable to reform itself, contemporary developments in Ireland, outside of psychiatry, appear to be forcing a more equitable and holistic mental health service. The main force of this reforming impetus is coming from clinical psychology.

Four significant developments have occurred in the last few years that have in effect challenged the hegemony of psychiatry and 'prescription pad therapy'. The first of these relates to the upgrading of clinical psychology courses from postgraduate diploma and masters level to doctorate status. These developments have included a lengthening of the duration of some courses, as well as an increased research component. Such moves follow a trend in the UK, and all three clinical psychology courses on the island of Ireland (Queen's, TCD and UCD) have been of doctorate status for some years now.

Two of the other three developments are related to pay 
awards and the career structure of clinical psychology. Clinical psychology received a significant pay award within the last two years that has undoubtedly increased the status of the profession. The relationship between salaries and status may be dismissed by some as shallow, but the reality remains that with the exception of a small number of occupations (for example clergy), and pariah groups, this relationship holds throughout our status-conscious society. The third development of relevance has been the introduction of the principal grade into the clinical psychology (interestingly in the UK this position is called 'consultant'). Clinical psychology now therefore has four grades of qualified staff: basic grade, senior, principal and head of service. As these principal positions become established throughout the country, multidisciplinary teams are coming to terms with input from more senior and influential clinical psychologists.

The final advance in clinical psychology has been the expansion in the number of approved posts throughout the country. This has led to an increasing input from clinical psychology in many areas where to date their experience and training has been absent.

Such developments in clinical psychology can be seen to represent a threat to the monopoly of authority held by psychiatry. Human emotions run deep and concern over status is perpetual. Therefore as inter-personal and interprofessional relations evolve, some degree of conflict (albeit covert) is inevitable. Thus one hears anecdotal stories of concerns within psychiatry over safeguarding 'doctors only common rooms', as well amusement at the idea of doctorates in clinical psychology. Stories abound of consultants refusing to use the title 'Dr' when addressing a clinical psychologist, or stating that having non-medical 'doctors' is confusing for patients. In such situations one can only muse at such concerns given the scarcity of MDs or PhDs, and plethora of MBs in our medical population.

However it is important not to focus too much on such conflicts. A number of die-hards may fight a failing rear-guard action against these developments. The real focus now should be towards the future. Clinical psychology can provide a much-needed balance to psychiatry to aid the development of more holistic mental health services for the benefit of patients. Challenging times lay ahead for both disciplines. Psychiatry must accommodate to the increased strength and influence of psychology, while psychology must prove itself able to meet the challenge of its increased status and responsibility. However if both disciplines can embrace a constructive partnership, based on increased equity and mutual respect, they will find it equally rewarding, enriching and successful.

It should be noted however that the development of clinical psychology outlined above has only started the process of introducing both increased equity and a more rounded approach into multidisciplinary teams. Much further work is needed to incorporate fully the skills and expertise of other professions such mental health nursing and social work, who are so often treated as the 'blue-collar' workers of mental health services. It is essential that both clinical psychology and psychiatry acknowledge this need, rather than simply cooperating to form a mutually beneficial alliance to dominate the other professions.

It would be misleading to finish without first outlining some of the challenges that are currently emerging within the field of psychology itself. Clinical psychology has to date largely managed to dominate the field of psychology within the health services. However their monopolisation of psychology within the health services fiefdom appears to have been overturned over the past year or so. Positions formerly advertised exclusively for clinical psychologists are now routinely inviting applications from other brands of psychology, especially counselling psychology. An examination of the self-defined areas of specialty of these two disciplines reveal how remarkably similar they are. It remains to be seen how these tensions will be resolved. Any realignment in areas of practice will probably be resisted. A rationalisation of this area however would do well to also include the sub-disciplines of health psychology and educational psychology. Similarly tensions exist within the current field of clinical psychology between those that have a doctorate in clinical psychology and those that do not. This does not merely reflect the date of training, as the current in-service training route for clinical psychologists run by the psychological society of Ireland is at postgraduate diploma level. There are widespread concerns that clinical psychology may as a result develop an internal two-tier hierarchy.

Frank Houghton Health Geographer, Department of Public Health, Mid Western Health Board, Limerick, Ireland. 